\title{
The method for Determining the Effectiveness of Low-Grade Geothermal Heat Usage under the Conditions of the Russian Climate
}

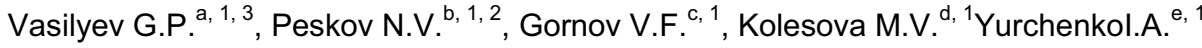 \\ ${ }^{1}$ JSC "INSOLAR-INVEST", Moscow, Russia \\ ${ }^{2}$ Faculty of Computational Mathematics and Cybernetics, Lomonosov Moscow State University, Moscow, Russia \\ ${ }^{3}$ JSC "NIIMosstroy", Moscow, Russia
}

\begin{abstract}
This paper reports the results of study on the effectiveness of using low-grade ground heat in heat pump systems under the climatic conditions of Russia. The study was performed to collect data for using the software package "INSOLAR.GSHP.12", which simulates the non-stationary thermal conditions of ground source heat pumps (GSHPs) over several years of operation.The described study was performed with the financial support of the Ministry of Education and Science of Russia. Contract ID RFMEFI57914X0026.
\end{abstract}

\section{Introduction.}

Currently, ground source heat pumps (GHSPs) are widely used in regions with moderate climates [1]. Unlike Russia, these regions have higher natural soil temperatures and relatively short heating seasons. These conditions make ground heat collection from soil at temperatures above zero possible.

During GSHP operation, the body of soil surrounding the ground heat exchanger is subject to multiple freezing and thawing events. Naturally, such events alter the state of matter of moisture contained in soil pores, which is generally present in liquid, solid, and gas states simultaneously. At the same time, the presence of moisture in a capillary-pore system has a considerable impact on the heat distribution process. In most regions of Russia, having low natural ground temperatures and long heating seasons, the use of GSHP at ground temperatures above zero is economically ineffective. Longstanding GSHP operation in the Russian geological and climatic conditions will usually face the problems of the freezing/thawing of soil adjacent to the borehole [2].

Another distinctive feature of the thermal conditions for underground structures as a simulation object is the so-called "informative uncertainty" of the mathematical models describing these processes. In other words, the lack of reliable information on how the environment (atmosphere and soil that is beyond the range of thermal influence of the underground structure) affects the system highlights the extreme complexity of the modeling of these impacts $[3,4]$.

\footnotetext{
${ }^{\mathrm{c}}$ Corresponding author: insolar-invest@yandex.ru

âGVassiliev@mail.ru;

bpeskovnick@gmail.com;

deco-insolar@mail.ru;

iyurchenko@insolar.ru
}

\section{A method of the mathematical simulation of the thermal conditions of a low-grade ground heat collection system.}

To overcome the above-mentioned difficulties, the authors of this paper created and tested a method of mathematically simulating the thermal conditions of a low-grade ground heat collection system.

The essence of the method is to consider in the simulation the difference between two problems: the "basic" problem, describing the undisturbed soil's thermal conditions (without the impact of the heat collection system's heat exchanger), and the problem in question, describing the thermal conditions of the body of soil with heat sinks (sources). The method allows for obtaining a solution regarding a new function that represents the impact of the heat sinks on the natural soil's thermal conditions and equals the difference between the natural soil's temperatures and the temperatures of soil containing heat sinks (sources). Using this method for simulating the thermal conditions of low-grade ground heat gathering systems enables the bypass of the difficulties associated with the approximation of external impacts on the heat collection system as well as the use of data regarding the soil's natural thermal conditions obtained from weather stations. The method makes it possible to partially take into account the whole range of factors (such as presence of the groundwater, it's speed and thermal conditions, the structure and location of the soil layers, the "thermal" background from the Earth, precipitation, phase transformation of moisture in the 
pore space, and more), which have a significant influence on the formation of the thermal regime of the tunnel but are almost impossible to account for simultaneously. The main advantage of this method is the use of temperature data obtained directly from weather stations instead of solving the "base" problem.

Tables 1-5 contain data on the average monthly ground temperatures at different depths for several Russian cities. Table 1 contains the average monthly ground temperatures for 23 Russian cities at a depth of 1.6 meters, which is the most appropriate for horizontal ground heat exchangers, based on the thermal potential of the soil and the possibilities of earthworks mechanization

Table 1.Average monthly ground temperature

\begin{tabular}{|c|c|c|c|c|c|c|c|c|c|c|c|c|}
\hline \multicolumn{8}{|c|}{ Average monthly ground temperatures at a depth of 16 m for several Russian cities [ ${ }^{0}$ C]. } \\
\hline & I & II & III & IV & V & VI & VII & VIII & IX & X & XI & XII \\
\hline Arkhangelsk & 4 & 3.5 & 3.1 & 2.7 & 2.5 & 3 & 4.5 & 6 & 7.1 & 7 & 6.1 & 4.9 \\
\hline Astrakhan & 7.5 & 6.1 & 5.9 & 7.3 & 11 & 14.6 & 17.4 & 19.1 & 19.1 & 16.7 & 13.6 & 10.2 \\
\hline Barnaul & 2.6 & 1.7 & 1.2 & 1.4 & 4.3 & 8.2 & 11 & 12.4 & 11.6 & 9.2 & 6.2 & 3.9 \\
\hline Bratsk & 0.4 & -0.2 & -0.6 & -0.5 & -0.2 & 0 & 3 & 6.8 & 7.2 & 5.4 & 2.9 & 1.4 \\
\hline Vladivostok & 3.7 & 2 & 1.2 & 1 & 1.5 & 5.3 & 9.1 & 12.4 & 13.8 & 12.7 & 9.7 & 6.4 \\
\hline Irkutsk & -0.8 & -2.8 & -2.7 & -1.1 & -0.5 & -0.2 & 1.7 & 5 & 6.7 & 5.6 & 3.2 & 1.2 \\
\hline Komsomolsk-on-Amur & 0.8 & -0.4 & -0.9 & -0.4 & 0 & 1.9 & 6.7 & 10.5 & 11.3 & 9 & 5.5 & 2.7 \\
\hline Magadan & -6.5 & -8 & -8.8 & -8.7 & -3.9 & -2.6 & -0.8 & 0.1 & 0.4 & 0.1 & -0.2 & -2 \\
\hline Moscow & 3.8 & 3.2 & 2.7 & 3 & 6.2 & 9.6 & 12.1 & 13.4 & 12.5 & 10.1 & 7.3 & 5 \\
\hline Murmansk & 0.7 & 0.3 & 0 & -0.3 & -0.3 & 0.2 & 4 & 6.7 & 6.6 & 4.2 & 2.7 & 1 \\
\hline Novosibirsk & 2.1 & 1.2 & 0.6 & 0.5 & 1.3 & 5 & 9.1 & 11.3 & 10.9 & 8.8 & 5.8 & 3.6 \\
\hline Orenburg & 4.1 & 2.6 & 1.9 & 2.2 & 4.9 & 8 & 10.7 & 12.4 & 12.6 & 11.2 & 8.6 & 6 \\
\hline Perm & 2.9 & 2.3 & 1.9 & 1.6 & 3.4 & 7.2 & 10.5 & 12.1 & 11.5 & 9 & 6 & 4 \\
\hline P.-Kamchatsky & 2.6 & 1.9 & 1.5 & 1.1 & 1.2 & 3.4 & 6.7 & 9.1 & 9.6 & 8.3 & 5.6 & 3.8 \\
\hline Rostov-on-Don & 8 & 6.6 & 5.9 & 6.8 & 9.9 & 12.9 & 15.5 & 17.3 & 17.5 & 15.8 & 13 & 10 \\
\hline Salekhard & 1.6 & 1 & 0.7 & 0.5 & 0.4 & 0.9 & 3.9 & 6.8 & 7.1 & 5.6 & 3.5 & 2.3 \\
\hline Sochi & 11.2 & 9.8 & 9.6 & 11 & 13.4 & 16.2 & 18.9 & 20.8 & 21 & 19.2 & 16.8 & 13.5 \\
\hline Turuhansk & 0.9 & 0.5 & 0.2 & 0 & 0 & 0.1 & 1.6 & 6.2 & 6.4 & 4.5 & 2.8 & 1.8 \\
\hline Tura & -0.9 & -0.3 & -5.2 & -5.3 & -3.2 & -1.6 & -0.7 & 1.2 & 2 & 0.7 & 0 & -0.2 \\
\hline Uelen & -6.9 & -8 & -8.6 & -8.7 & -6.3 & -1.2 & -0.4 & 0.1 & 0.2 & 0 & -0.8 & -3.7 \\
\hline Khabarovsk & 0.3 & -1.8 & -2.3 & -1.1 & -0.4 & 2.5 & 9.5 & 13.3 & 13.5 & 10.9 & 6.7 & 3 \\
\hline Yakutsk & -5.6 & -7.4 & -7.9 & -7 & -4.1 & -1.8 & 0.3 & 1.5 & 1.1 & 0.1 & -0.1 & -2.4 \\
\hline Yaroslavl & 2.8 & 2.2 & 1.9 & 1.7 & 3.9 & 7.8 & 10.7 & 12.4 & 11.5 & 9.5 & 6.3 & 3.9 \\
\hline
\end{tabular}

Table 2.Ground temperature in Stavropol (soil - chernozem)

\begin{tabular}{|c|c|c|c|c|c|c|c|c|c|c|c|c|}
\hline Depth $(\mathrm{m})$ & I & II & III & IV & V & VI & VII & VIII & IX & X & XI & XII \\
\hline 0.4 & 1.2 & 1.3 & 2.7 & 7.7 & 13.8 & 17.9 & 20.3 & 19.6 & 15.4 & 11.4 & 6 & 2.8 \\
\hline 0.8 & 3 & 1.9 & 2.5 & 6 & 11.5 & 15.4 & 17.6 & 17.6 & 15.3 & 12.2 & 7.8 & 4.6 \\
\hline 1.6 & 5 & 4 & 3.8 & 5.3 & 8.8 & 12.2 & 14.4 & 15.7 & 15.1 & 12.7 & 9.7 & 6.8 \\
\hline 3.2 & 8.9 & 8 & 7.4 & 7.4 & 8.4 & 9.9 & 11.3 & 12.6 & 13.2 & 12.7 & 11.6 & 10.1 \\
\hline
\end{tabular}

Table 3.Ground temperatures in Yakutsk (soil-silty-sand with an admixture of humus with sand beneath)

\begin{tabular}{|c|c|c|c|c|c|c|c|c|c|c|c|c|}
\hline Depth $(\mathrm{m})$ & I & II & III & IV & V & VI & VII & VIII & IX & X & XI & XII \\
\hline 0.2 & -19.2 & -19.4 & -16.2 & -7.9 & 4.3 & 13.4 & 17.5 & 15.5 & 7 & -3.1 & -10.8 & -15.6 \\
\hline 0.4 & -16.8 & 17.4 & -15.2 & -8.4 & 2.5 & 11 & 15 & 13.8 & 6.7 & -1.9 & -8 & -12.9 \\
\hline 0.6 & -14.3 & -15.3 & -13.7 & -8.5 & 0.2 & 7.9 & 12.1 & 11.8 & 6.2 & -0.5 & -5.2 & -10.3 \\
\hline 0.8 & -12.4 & -14.1 & -12.7 & -8.4 & -1.4 & 5 & 9.4 & 9.6 & 5.3 & 0 & -3.4 & -8.1 \\
\hline 1.2 & -8.7 & -10.2 & -10.2 & -8 & -3.3 & 0.1 & 4.1 & 5 & 2.8 & 0 & -0.9 & -4.9 \\
\hline 1.6 & -5.6 & -7.4 & -7.9 & -7 & -4.1 & -1.8 & 0.3 & 1.5 & 1.1 & 0.1 & -0.1 & -2.4 \\
\hline 2.4 & -2.6 & -4.4 & -5.4 & -5.6 & -4.4 & -3 & -2 & -1.4 & -1 & -0.9 & -0.9 & -1 \\
\hline 3.2 & -1.7 & -2.6 & -3.8 & -4.4 & -4.2 & -3.4 & -2.8 & -2.3 & -1.9 & -1.8 & -1.6 & -1.5 \\
\hline
\end{tabular}


Table 4.Ground temperatures in Pskov (soil-loam with clay beneath)

\begin{tabular}{|c|c|c|c|c|c|c|c|c|c|c|c|c|}
\hline Depth $(\mathrm{m})$ & I & II & III & IV & V & VI & VII & VIII & IX & X & XI & XII \\
\hline 0.2 & -0.8 & -1.1 & -0.3 & 3.3 & 11.4 & 15.1 & 19 & 17.2 & 12.3 & 6.7 & 2.6 & 0.2 \\
\hline 0.4 & 0.6 & 0 & 0 & 2.4 & 9.6 & 13.5 & 16.9 & 16.5 & 12.9 & 7.8 & 4.2 & 1.7 \\
\hline 0.8 & 1.7 & 0.9 & 0.8 & 2 & 7.8 & 11.6 & 15 & 15.6 & 13.2 & 8.8 & 5.4 & 2.9 \\
\hline 1.6 & 3.2 & 2.4 & 1.9 & 2.2 & 5.6 & 9.2 & 11.9 & 13.2 & 12 & 9.7 & 6.9 & 4.6 \\
\hline
\end{tabular}

Table 5.Ground temperature in Vladivostok (brown bulk rocky soil)

\begin{tabular}{|c|c|c|c|c|c|c|c|c|c|c|c|c|}
\hline Depth $(\mathrm{m})$ & I & II & III & IV & V & VI & VII & VIII & IX & X & XI & XII \\
\hline 0.2 & -6.1 & -5.5 & -1.3 & 2.7 & 9.3 & 14.8 & 18.9 & 21.2 & 18.4 & 11.6 & 3.2 & -2.3 \\
\hline 0.4 & -3.7 & -3.8 & -1.1 & 1 & 7.3 & 12.7 & 16.7 & 19.5 & 17.5 & 12.3 & 5.2 & 0.2 \\
\hline 0.8 & -0.1 & -1.4 & -0.6 & 0 & 4.4 & 10.4 & 14.2 & 17.3 & 17 & 13.5 & 7.8 & 2.9 \\
\hline 1.6 & 3.6 & 2 & 1.3 & 1.1 & 2.9 & 7.7 & 11 & 14.2 & 15.4 & 13.8 & 10.2 & 6.4 \\
\hline 3.2 & 8 & 6.4 & 5.2 & 4.4 & 4.2 & 5.5 & 7.5 & 9.4 & 11.3 & 12.4 & 11.7 & 10 \\
\hline
\end{tabular}

Data on natural temperature levels in soil at depths up to $3.2 \mathrm{~m}$ (i.e., "operational" soil layer for GSHP with horizontal heat exchanger) contained in the tables indicate the possibilities of using the ground as a source of low-grade heat. It is obvious that the temperature gradient over the territory of Russia for soil layers of the same depth is relatively small. For example, in Stavropol, the minimal temperature at the depth of $3.2 \mathrm{~m}$ is $7.4^{\circ} \mathrm{C}$, and in Yakutsk, it is $-4.4{ }^{\circ} \mathrm{C}$; thus, the temperature gradient for this depth is $11.8^{\circ} \mathrm{C}$. This offers a chance to develop rather unified equipment that is suitable for use almost all over the territory of Russia.

The peculiarity of the natural temperature regime of the soil, as seen from the tables, is the lag of the minimal soil temperatures, relative to the time of the minimal ambient air temperature. The minimal ambient air temperatures are registered during January, while minimal ground temperatures at a depth of $1.6 \mathrm{~m}$ are registered during March in Stavropol, Yakutsk and Sochi as well as during April in Vladivostok. Thus, it is obvious that when the ground temperature has reached its minimum, the load on the heat pump system (heat loss of a building) is not at its highest. This creates possibilities for reducing the design capacity of the GSHP (saving capital investments). This should be of concern during system design.

\section{Conclusions.}

The accumulated data allows performing calculations for different regions of Russia, allowing to estimate the effectiveness of GSHP usage in different conditions. This opens vast research opportunities, including, but not limited to, the zoning of the territory of Russia, according to the effectiveness of use of low-grade ground heat for heating of buildings. This provides a more complex approach to GSHP usage and allows to use them more effectively.

\section{Acknowledgements:}

This paper contains the results of research performed with financial support from the Ministry of Education and Science of the Russian Federation on the subject of the «Development of principles and methods for creating adaptive Ground source heat pumps, harmonized with power load cycles of heated or cooled facilities»", contract ID RFMEFI57914X0026.

\section{References}

1. Lund J.W., Freeston D.H., Boyd T.L.Direct utilization of geothermal energy 2010 worldwide review. Geothermics, 40 (2011) 159-180.

2. Vasilyev G.P. Heat and cold buildings and structures using low-grade heat energy of the surface layers of the Earth (Monograph). Publishing house "Border". M., "Red Star" - 2006. - 220.

3. Gupta S.C. The classical Stefan problem: basic concepts, modeling and analysis. Elsevier, 2003.

4. Yang H., Cui P., Fang Z. Vertical-borehole groundcoupled heat pumps: A review of models and systems, Applied Energy, 87 (2010) 16-27.

5. Sanner B. Ground Heat Sources for Heat Pumps (classification, characteristics, advantages). Course on geothermal heat pumps, 2002. 